\title{
Geographical cline in breeding systems and ploidy levels in European populations of Daphnia pulex
}

\author{
ROBERT D. WARD*, MELANIE A. BICKERTON $\ddagger$ TERRIE FINSTON $\uparrow \&$ PAUL D. N. \\ HEBERT† \\ Department of Human Sciences, Loughborough University of Technology, Loughborough LE11 3TU, U.K. and \\ $\dagger$ Department of Zoology, University of Guelph, Guelph, Ontario, N1G 2W1, Canada
}

\begin{abstract}
Ninety populations of Daphnia pulex from sites throughout the UK and Scandinavia were assayed for genetic variation at 11 variable enzyme loci. A latitudinally-related cline in both breeding system and ploidy level was observed. Southern populations (latitudes $52-59^{\circ} \mathrm{N}$ ) comprised only diploid cyclic parthenogens. Northern populations (latitudes $68-71^{\circ} \mathrm{N}$ ) were dominated by polyploid obligate parthenogens and diploid cyclic parthenogens were absent. An assemblage of populations from a site of intermediate latitude $\left(61^{\circ} \mathrm{N}\right)$ included both diploid cyclic parthenogens and diploid obligate parthenogens. This cline parallels one previously described from temperate to arctic North America. The obligately parthenogenetic (asexual) clones were generally heterozygous at one or more loci for a common $D$. pulex allele plus an allele not found in cyclically parthenogenetic (sexual) populations of $D$. pulex: it is argued that these asexual clones arose polyphyletically following several independent hybridizations between $D$. pulex and an unrecognized but closely related taxon. Fifteen different asexual clones were detected and 25 of 28 asexual populations were uniclonal: the mean number of asexual clones per population was 1.21.
\end{abstract}

Keywords: allozymes, breeding systems, clones, Daphnia pulex, polyploidy, parthenogenesis.

\section{Introduction}

There are many unanswered questions concerning the origin and maintenance of recombination and sexual reproduction and the relative advantages and disadvantages of asexual reproduction (Williams, 1975; Maynard Smith, 1978; Bell, 1982). Asexual or parthenogenetic reproduction is frequently associated with high latitudes or higher altitudes (Vandel, 1928), an association which has been attributed to the relatively simple biotic complexity of habitats in these regions (Glesener \& Tilman, 1978) compared with, say, tropical rain forests. However, most obligately asexual organisms are polyploid and it may be that the prevalence of parthenogenesis in such habitats arises indirectly through selection for elevated ploidy levels (Suomalainen, 1962, 1969).

Cladocerans exhibit a variety of reproductive modes and have been the focus of several studies concerned

*Correspondence: CSIRO Fisheries, GPO Box 1538, Hobart, Tasmania 7001, Australia.

$\ddagger$ Present address: Department of Geography, Loughborough University of Technology, Loughborough LE1 1 3TU, U.K. with the distribution and evolution of breeding system variation. In these organisms, cyclic parthenogenesis (whereby both sexual and asexual phases occur in the life cycle) is widespread, although some species are obligate parthenogens. The cladoceran which has attracted most attention in recent years is Daphnia pulex. Populations of this species in the USA and southern Canada are diploid and may be either cyclically or obligately parthenogenetic (Lynch, 1983; Hebert et al., 1988, 1989a, 1993), while in the low Arctic regions of Canada diploid and polyploid obligate parthenogens predominate and in the high Arctic the great majority of animals are polyploid obligate parthenogens (Weider et al., 1987; Beaton \& Hebert, 1988).

Most studies of $D$. pulex have thus far focused on North American populations, although the species is widespread and abundant in small freshwater bodies throughout the Holarctic region. In Europe, four Czechoslovakian populations (Hebert et al., 1989b) showed very little genetic variation: a result suggestive (but hardly conclusive) of cyclic parthenogenesis, as obligately parthenogenetic $D$. pulex typically show fixed heterozygosity at several loci. Two English populations 
were unambiguously identified as cyclic parthenogens, as both populations were in Hardy-Weinberg equilibrium and breeding tests demonstrated segregation in the progeny of ephippial hatchlings of heterozygous mothers (Ward \& Geissler, 1988). Populations from central Russia (Novosibirsk) have also been identified as cyclic parthenogens (Ruvinsky et al., 1986).

The present paper presents the results of a survey investigating whether there is a north-south cline in breeding system and polyploidy in European populations of $D$. pulex. To this end, the genetic structures of 43 British populations and 47 Scandinavian populations were investigated, at latitudes ranging from $52^{\circ} \mathrm{N}$ to well above the Arctic circle at $71^{\circ} \mathrm{N}$.

\section{Materials and methods}

Samples from 43 UK populations were collected in 1987 and 1988. These ranged in latitude from approximately $52^{\circ} \mathrm{N}$ (Gwent, South Wales) to approximately $57^{\circ} \mathrm{N}$ (mid-Scotland). Most of these populations were from rural or farmed areas and, although a few came from permanent ponds, the great majority were from small, intermittent, habitats.

Samples from 47 Scandinavian populations (Fig. 1) were collected in the summer of 1989. These ranged in latitude from approximately $56^{\circ} \mathrm{N}$ (Helsingor, Denmark) to approximately $71^{\circ} \mathrm{N}$ (north Norway). The two most southerly Scandinavian populations, those from Denmark (population 1, latitude $56^{\circ} \mathrm{N}$ ) and Sweden (Tjarno, population 2, latitude $59^{\circ} \mathrm{N}$ ) were from farmed, rural areas. One north Norwegian population (number 47 , latitude $71^{\circ} \mathrm{N}$ ) was located in tundra a few hundred metres from the sea. All other Scandinavian populations were located in rock bluff pools no more than a few metres above maximum sea level and each was no more than a few square metres in area. Ten such populations (numbers 3-12) were collected in the southwestern archipelago of Finland, about $30 \mathrm{~km}$ west of Turku (latitude $61^{\circ} \mathrm{N}$ ), nineteen (numbers $13-31$ ) in the vicinity of Narvik, mid-Norway (latitude $68^{\circ} 30^{\prime} \mathrm{N}$ ), and 15 (numbers 32-46) from north Norway (latitude $71^{\circ} \mathrm{N}$ ). All the Scandinavian populations would either have dried up in late summer or would have frozen solid in the winter: they were all intermittent populations founded each year from overwintering ephippial eggs.

All samples were collected using dip nets and stored in liquid nitrogen prior to electrophoretic analysis. Subsamples from some ponds were used for laboratory breeding experiments.

A sample of 44 individuals from each population was screened electrophoretically, with each individual being examined for the products of 11 loci. These loci were: $A P-1$ (a slow migrating aminopeptidase, E.C. 3.4.11.-), $A P-2$ (a fast migrating aminopeptidase, E.C. 3.4.11.-) (both aminopeptidases used phenylalanyl leucine as the dipeptide substrate), MPI (mannosephosphate isomerase, E.C. 5.3.1.8), PGI (phosphoglucose isomerase, E.C. 5.3.1.9), PGM (phosphoglucomutase, E.C. 5.4.2.2), LDH (lactate dehydrogenase, E.C. 1.1.1.27), $M D H$ (malate dehydrogenase, E.C. 1.1.1.37), $A O$ (aldehyde oxidase, E.C. 1.2.3.1), FUM (fumarase, E.C. 4.2.1.2), $A A T$ (aspartate aminotranferase, E.C. 2.6.1.1) and $A M Y$ (amylase, E.C. 3.2.1.1) Titan III cellulose acetate gels (Helena Labs) and a Tris-glycine buffer system were used for all enzymes (Hebert \& Beaton, 1989).

For each population sample, the genotype diversity ratio (GDR) was estimated. The observed number of electrophoretically distinct genotypes was compared with the number expected in a Hardy-Weinberg equilibrium sample of that given size (44) and given allele frequencies. This expected number was derived by computer simulation, each simulation being run 100 times to produce a mean value. Dividing the observed number of genotypes by the mean expected number gives the GDR. Note that for a population homozygous at all loci, the GDR will equal one and is not informative with respect to breeding system designation. However, for populations showing genetic variation the GDR is informative: it should be close to 1 in a sexually reproducing (cyclically parthenogenetic) population but considerably less than one in an obligately parthenogenetic population. These expectations arise because cyclically parthenogenetic populations produce resting (ephippial) eggs sexually, meaning that all such populations of an intermittent nature will be founded anew each year from sexually derived eggs whereas obligately parthenogenetic populations produce resting eggs asexually.

In order to confirm breeding system type, heterozygous clones from some samples were established in the laboratory and ephippial eggs or ephippial hatchlings analysed. In a cyclic parthenogen, the ephippia are produced sexually and will show segregation whereas in an obligate parthenogen they are produced asexually and the markers will not segregate.

Ploidy levels were estimated both from gel staining patterns and from estimates of genome size. Asymmetrically staining or 'unbalanced' heterozygote patterns were observed for several loci $(A P-2, P G M$, $L D H$ and $A A T)$ in several of the Scandinavian clones and were attributed to polyploidy. Such patterns are not observed in diploid clones (present study; Weider et al., 1987; Weider \& Hebert, 1987; Beaton \& Hebert, 1988). Unfortunately, ploidy levels cannot be directly assigned from gel patterns. Some clones exhibited 


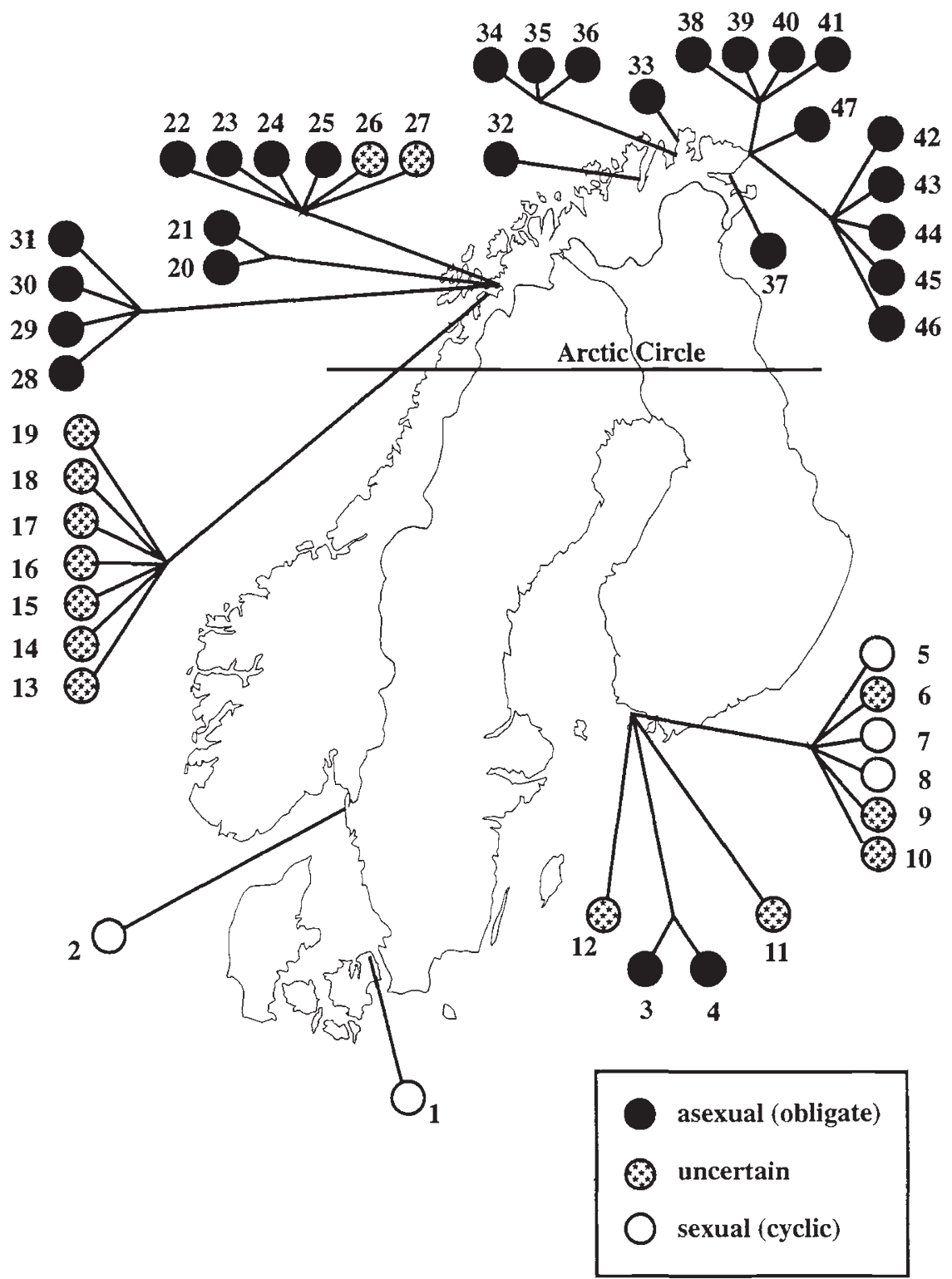

Fig. 1 Locations and reproductive modes of the Scandinavian populations. Populations branching from a ommon node are from the same rock bluff. balanced heterozygotes for some loci and unbalanced heterozygotes for others. Such clones could either be triploid clones, with the unbalanced heterozygotes resulting from two doses of one allele and one dose of another and the balanced heterozygotes resulting from one null and two active alleles, or tetraploids with the balanced heterozygotes resulting from two doses of each of two alleles and the unbalanced heterozygotes resulting from one and three doses (or possibly one and two doses along with a null allele). Heterozygote patterns at two loci, $A O$ and $A M Y$, could not be confidently identified as being balanced or unbalanced and were not used in ploidy estimates.
DNA quantification was carried out using scanning microdensitometry of individual Feulgen-stained nuclei. Ten to twelve individuals from each sample were fixed for $1 \mathrm{~h}$ in a 3:1 solution of methanol:glacial acetic acid. They were then transferred to 70 per cent ethanol and held in the dark at $4^{\circ} \mathrm{C}$ until staining. Each run also contained a known diploid $D$. pulex standard from Windsor, Ontario (clone W2-8). A dilution series of 50 per cent and 20 per cent ethanol was used before transferring the animals to distilled water for $30 \mathrm{~min}$. The animals were then hydrolyzed in $5 \mathrm{~N} \mathrm{HCl}$ for 30 min and Feulgen stained in the dark for $100 \mathrm{~min}$. The animals were rinsed in three sulphite and three water 
washes and stored in 20 per cent ethanol. The third and fourth thoracic limbs were excised from a minimum of three individuals per sample and allowed to air dry on a microscope slide. The exopodites were chosen for analysis as they contain an abundance of diploid nuclei and no endopolyploid nuclei (Beaton \& Hebert, 1990). Integrated optical densities of ten nuclei from each of the three individuals were obtained at $1000 \times$ using a Wild-Leitz/DADS scanning microdensitometer system. Mean optical density (OD) units were calculated for all samples and the standard. To obtain DNA contents in picograms for the unknown samples, the number of picograms per OD unit in the W2-8 standard was calculated by dividing the DNA value of the diploid W2-8 nuclei of $0.74 \mathrm{pg}$ (Beaton \& Hebert, 1990) by the mean OD value of the thirty nuclei. Ploidy levels of unknown samples were calculated by dividing sample mean OD units by one-half of the value in OD units obtained for the diploid W2-8 standard.

\section{Results}

\section{Population structure of the UK populations}

Forty-three UK populations of $D$. pulex were examined. These results will be presented in detail elsewhere but the main findings are given here. Thirteen of the populations were homozygous at each locus and therefore breeding systems could not be identified. Five populations showed significant deviations from Hardy-Weinberg equilibrium but these were all from larger, probably permanent, water bodies in which parthenogenetic reproduction is expected to dominate any sexual recruitment. The 25 remaining populations, ranging in latitude from central England to northern Scotland, had genotype frequencies which did not deviate from Hardy-Weinberg equilibrium and are assumed to reproduce by cyclic parthenogenesis. Heterozygous clones, established from eight populations (two from the English Midlands, two from North England and four from Scotland), showed segregation of ephippial hatchlings (Ward \& Geissler, 1988; M. A. Bickerton, unpublished data). There was no evidence that any of the UK populations reproduced by other than cyclic parthenogenesis and the lack of unbalanced heterozygotes at any locus was consistent with all these individuals being diploid.

\section{Population structure of Scandinavian populations}

The one population sampled from Denmark was segregating for two alleles at four loci (MPI, FUM, $A O$ and $A M Y)$. Twenty-five different multilocus genotypes were detected and at each locus genotype numbers approximated Hardy-Weinberg expectations $(G D R=1.121)$. The one population sampled from southern Sweden (Table 1) was polymorphic for $A P-2$ and in Hardy-Weinberg equilibrium $(\mathrm{GDR}=1.003)$. Both these populations are assumed to reproduce by cyclic parthenogenesis.

Three of the ten populations (numbers 3-12) in the southwestern archipelago of Finland were polymorphic (Table 1). Two of these populations (7 and 8) were polymorphic for $M D H$, showed no deviations from Hardy-Weinberg equilibrium and consequently had GDRs close to unity: they are likely to be cyclic parthenogens. The third population (5) was polymorphic for $A O$. It showed significant deviations from Hardy-Weinberg equilibrium $(P=0.001)$ but had a high GDR $(0.67)$ and was genetically similar to populations 7 and 8: it is assumed to be a cyclic parthenogen that through drift or selection had deviated from equilibrium since the initiation of the new population in the spring from ephippial eggs. Five other populations $(6$, 9-12) were homozygous at each locus and their breeding system is therefore classified as 'uncertain'. However, as two of these populations (6 and 12) were fixed for a clone $(\mathrm{c} 7)$ that was genetically identical to one of those present in 7 and 8 , it is likely that they were also sexually derived. Populations 9 and 10 comprised a single homozygous genotype (c10) and population 11 likewise comprised a single homozygous genotype: their breeding system has been designated as uncertain. The two remaining populations ( 3 and 4 ) from this archipelago, isolated from adjacent rock pools on the same island, were clearly asexual. Both populations contained the same clone (c4) with fixed heterozygosity at three loci and consequently a low GDR $(0.05)$. The balanced nature of the heterozygotes at these three loci ( $L D H, A A T$ and $A O$ ) is consistent with, but does not prove, diploidy. In summary, of these ten southern Finnish populations, three were cyclic parthenogens, two were obligate parthenogens and five were of uncertain breeding system.

Moving further north, 19 populations (numbers 13-31) were sampled in the vicinity of Narvik, midnorth Norway (Table 2). The first seven of these (13-19) were on a single rock bluff, with six populations uniclonal for the same clone, c6b, and one population comprising a different although closely related clone, $\mathrm{c} 11 \mathrm{~b}$. These two clones were multiply homozygous and are of uncertain breeding system, although the more common of the two (c6b) had the same genotype as a clone assumed to be a cyclic parthenogen in southern Finland (c6a). Clone 6b was also present in two populations (26 and 27) on another rock bluff some tens of kilometres to the north. The second clone, c11b, had the same genotype as clone c11a from southern Finland, itself regarded as of 
Table 1 Genotypes observed in Daphnia pulex populations collected from south Sweden and the Baltic southwestern archipelago of Finland, near Turku

\begin{tabular}{|c|c|c|c|c|c|c|c|c|c|c|c|c|}
\hline Populations & $N$ & $A P-2$ & $A P-1$ & $M P I$ & $P G I$ & $M D H$ & $L D H$ & $A O$ & $A A T$ & $A M Y$ & GDR & Clone \\
\hline \multicolumn{13}{|c|}{ South Sweden } \\
\hline 1 & 2 & $83 / 83$ & $112 / 112$ & $108 / 108$ & $90 / 90$ & $80 / 80$ & $100 / 100$ & $104 / 104$ & $100 / 100$ & $100 / 100$ & \multirow[t]{3}{*}{1.003} & $\mathrm{c} 1$ \\
\hline & 25 & $83 / 100$ & $2 / 112$ & $108 / 108$ & $90 / 90$ & $80 / 80$ & $100 / 100$ & $104 / 104$ & $100 / 100$ & $100 / 100$ & & $c 2$ \\
\hline & 17 & $100 / 100$ & $112 / 112$ & $108 / 108$ & $90 / 90$ & $80 / 80$ & $100 / 100$ & $104 / 104$ & $100 / 100$ & $100 / 100$ & & $\mathrm{c} 3$ \\
\hline \multicolumn{13}{|c|}{ Baltic southwestern archipelago of Finland } \\
\hline 3,4 & 44 & $90 / 90$ & $112 / 112$ & $100 / 100$ & $101 / 101$ & $80 / 80$ & $100 / 125$ & $115 / 115$ & $100 / 115$ & $100 /-10$ & 0.051 & $\mathrm{c} 4$ \\
\hline \multirow[t]{2}{*}{5} & 29 & $100 / 100$ & $100 / 100$ & $108 / 108$ & $90 / 90$ & $80 / 80$ & $100 / 100$ & $96 / 104$ & $100 / 100$ & $100 / 100$ & \multirow[t]{2}{*}{0.673} & c5 \\
\hline & 15 & $100 / 100$ & $100 / 100$ & $108 / 108$ & $90 / 90$ & $80 / 80$ & $100 / 100$ & $96 / 96$ & $100 / 100$ & $100 / 100$ & & c6a \\
\hline 6,12 & 44 & $100 / 100$ & $100 / 100$ & $108 / 108$ & $90 / 90$ & $80 / 80$ & $100 / 100$ & $104 / 104$ & $100 / 100$ & $100 / 100$ & (1) & c7 \\
\hline \multirow[t]{3}{*}{7} & 6 & $100 / 100$ & $100 / 100$ & $108 / 108$ & $90 / 90$ & $100 / 100$ & $100 / 100$ & $104 / 104$ & $100 / 100$ & $100 / 100$ & \multirow[t]{3}{*}{1.000} & $\mathrm{c} 8$ \\
\hline & 20 & & & & & $80 / 100$ & $100 / 100$ & $104 / 104$ & $100 / 100$ & $100 / 100$ & & c9 \\
\hline & 18 & $100 / 100$ & $100 / 100$ & $108 / 108$ & $90 / 90$ & $80 / 80$ & $100 / 100$ & $104 / 104$ & $100 / 100$ & $100 / 100$ & & c7 \\
\hline \multirow[t]{3}{*}{8} & 32 & $100 / 100$ & $100 / 100$ & $108 / 108$ & & $100 / 100$ & & & & & \multirow[t]{3}{*}{1.136} & c8 \\
\hline & 10 & & & & & & & & & & & c9 \\
\hline & 2 & $100 / 100$ & $100 / 100$ & $108 / 108$ & $90 / 90$ & $80 / 80$ & $100 / 100$ & $104 / 104$ & $100 / 100$ & $100 / 100$ & & c7 \\
\hline 9,10 & 44 & $100 / 100$ & $112 / 112$ & $108 / 108$ & $90 / 90$ & $100 / 100$ & $100 / 100$ & $104 / 104$ & $100 / 100$ & $100 / 100$ & (1) & $\mathrm{c} 10$ \\
\hline 11 & 44 & $100 / 100$ & $112 / 112$ & $108 / 108$ & $90 / 90$ & $80 / 80$ & $100 / 100$ & $96 / 96$ & $100 / 100$ & $100 / 100$ & (1) & c1la \\
\hline
\end{tabular}

All samples were fixed for PGM 100 and FUM 100. No 'unbalanced' heterozygotes were observed.

Table 2 Genotypes observed in Daphnia pulex populations collected from midnorth Norway, near Narvik

\begin{tabular}{|c|c|c|c|c|c|c|c|c|c|c|c|}
\hline Populations & $N$ & $A P-2$ & $A P-1$ & $M P I$ & $P G I$ & $P G M$ & $L D H$ & $A O$ & $A A T$ & GDR & Clone \\
\hline $13-16,18,19,26,27$ & 44 & $100 / 100$ & $100 / 100$ & $108 / 108$ & $90 / 90$ & $100 / 100$ & $100 / 100$ & $96 / 96$ & $100 / 100$ & (1) & $c 6 b$ \\
\hline 17 & 44 & $100 / 100$ & $112 / 112$ & $108 / 108$ & $90 / 90$ & $100 / 100$ & $100 / 100$ & $96 / 96$ & $100 / 100$ & (1) & $\mathrm{c} 11 \mathrm{~b}$ \\
\hline 20,21 & 44 & $90 / 100$ & $112 / 112$ & $100 / 100$ & $100 / 100$ & $92 / 100$ & $100 / 125$ & $115 / 115$ & $\mathbf{1 0 0} / 115$ & 0.032 & $\mathrm{c} 12$ \\
\hline 22,25 & 44 & $90 / 90$ & $112 / 112$ & $100 / 100$ & $90 / 100$ & $92 / 100$ & $100 / 125$ & $104 / 115$ & $100 / 115$ & 0.026 & c13 \\
\hline 23 & $\begin{array}{r}43 \\
1\end{array}$ & $\begin{array}{c}90 / 90 \\
100 / 100\end{array}$ & $\begin{array}{l}112 / 112 \\
100 / 100\end{array}$ & $\begin{array}{l}100 / 100 \\
108 / 108\end{array}$ & $\begin{array}{l}90 / 100 \\
90 / 90\end{array}$ & $\begin{array}{r}92 / 100 \\
100 / 100\end{array}$ & $\begin{array}{l}100 / 125 \\
100 / 125\end{array}$ & $\begin{array}{c}104 / 115 \\
96 / 96\end{array}$ & $\begin{array}{l}100 / 115 \\
100 / 100\end{array}$ & 0.025 & $\begin{array}{l}\text { c13 } \\
\text { c14 }\end{array}$ \\
\hline 24 & $\begin{array}{r}34 \\
6 \\
4\end{array}$ & $\begin{array}{c}90 / 90 \\
100 / 100 \\
100 / 100\end{array}$ & $\begin{array}{l}112 / 112 \\
100 / 100 \\
100 / 100\end{array}$ & $\begin{array}{l}100 / 100 \\
100 / 100 \\
100 / 100\end{array}$ & $\begin{array}{l}90 / 100 \\
90 / 90 \\
90 / 90\end{array}$ & $\begin{array}{r}92 / 100 \\
100 / 100 \\
100 / 100\end{array}$ & $\begin{array}{l}100 / 125 \\
100 / 125 \\
100 / 100\end{array}$ & $\begin{array}{c}104 / 115 \\
96 / 96 \\
96 / 96\end{array}$ & $\begin{array}{l}100 / 115 \\
100 / 100 \\
100 / 100\end{array}$ & 0.023 & $\begin{array}{l}\mathrm{c} 13 \\
\mathrm{c} 15 \\
\mathrm{c} 16\end{array}$ \\
\hline $28-31$ & 44 & $90 / 100$ & $112 / 112$ & $100 / 100$ & $100 / 100$ & $100 / 100$ & $100 / 125$ & $104 / 115$ & $100 / 115$ & 0.032 & $\mathrm{c} 17$ \\
\hline
\end{tabular}

All clones were fixed for $A M Y 100, M D H 80$ and FUM 100.

The bold allele in a heterozygote indicates that allele is probably present in more than one dose, leading to an 'unbalanced' heterozygote.

uncertain breeding type. Additional loci would have to be sampled to confirm that clones $6 \mathrm{a}$ and $6 \mathrm{~b}$, and c11a and $\mathrm{c} 11 \mathrm{~b}$, are indeed genetically identical.

Populations 20 and 21 were located in pools on the same rock bluff. Each was uniclonal for the same clone, with unbalanced phenotypes at each of the four heterozygous loci and a GDR of 0.03 . This clone, c12, is assumed to be a polyploid obligate parthenogen. Populations 22-25, located on the same rock bluff, were dominated by clone $\mathrm{c} 13$, heterozygous at five loci. 
At four of these loci, heterozygotes were balanced, while at the fifth heterozygous locus, $A O$, balanced and unbalanced heterozygotes cannot be reliably discriminated. This clone is clearly an obligate parthenogen but whether it is diploid or tetraploid cannot be determined from these data alone. Populations 23 and 24 contained a small number of three other clones $(\mathrm{c} 14$, c15 and c16). Clones c14 and c15 were heterozygous for $L D H$ alone and c16 was homozygous for all loci. These minor clones were only distantly related to the dominant clone $\mathrm{c} 13$ (Fig. 2), and although they cluster with the cyclic parthenogenetic clones (Fig. 2), their breeding system cannot be reliably assigned. Four ponds on another bluff (28-31) contained only c17, which was multiply heterozygous for four loci. At three of these loci, heterozygotes were unbalanced while the fourth heterozygous locus was $A O$. This was clearly another obligately parthenogenetic polyploid clone.

In summary, of the nineteen populations from midnorth Norway, six were obligately parthenogenetic polyploids, four were obligate parthenogens of uncertain ploidy status and nine possessed an uncertain breeding system.

In far-north Norway, 15 of 16 ponds sampled (population numbers 32-47) were uniclonal for one of seven obligately parthenogenetic polyploid clones (Table 3). These clones were each heterozygous for between three and five loci and had GDRs ranging from 0.050 to 0.026 . Populations 32-46 all occupied shallow rock bluff pools, very close to the sea. Number 47 was quite different. This pond was about $3 \mathrm{~m}$ in diameter and $2 \mathrm{~m}$ deep, probably of human origin, and was located in tundra a few hundred metres from the sea. Four different clones were present, with clone c25 dominating. Interestingly, although situated within a kilometre of populations 38-46, which themselves shared some clones, all four clones in population 47 were unique to this pond. Each of these appeared to be an obligate parthenogen, three being definite polyploids (c25, c26, c28) while the ploidy status of c27 was uncertain. Seven of the 11 clones observed in this northern region (c18, c22, c23, c24, c25, c26, c28) showed both unbalanced and balanced heterozygotes.

The data from far-north Norway suggest that all $D$ pulex at this latitude are obligate parthenogens, with diploids being rare or absent.

In total, 28 Scandinavian populations were identified as reproducing by obligate parthenogenesis. Twenty-five of these populations were uniclonal and the mean number of clones per population was 1.21 . Fifteen obligate parthenogenetic clones were identified. Each of these 15 clones was very restricted in distribution, with all but one being found only on one particular rock bluff. The exception was clone c23,

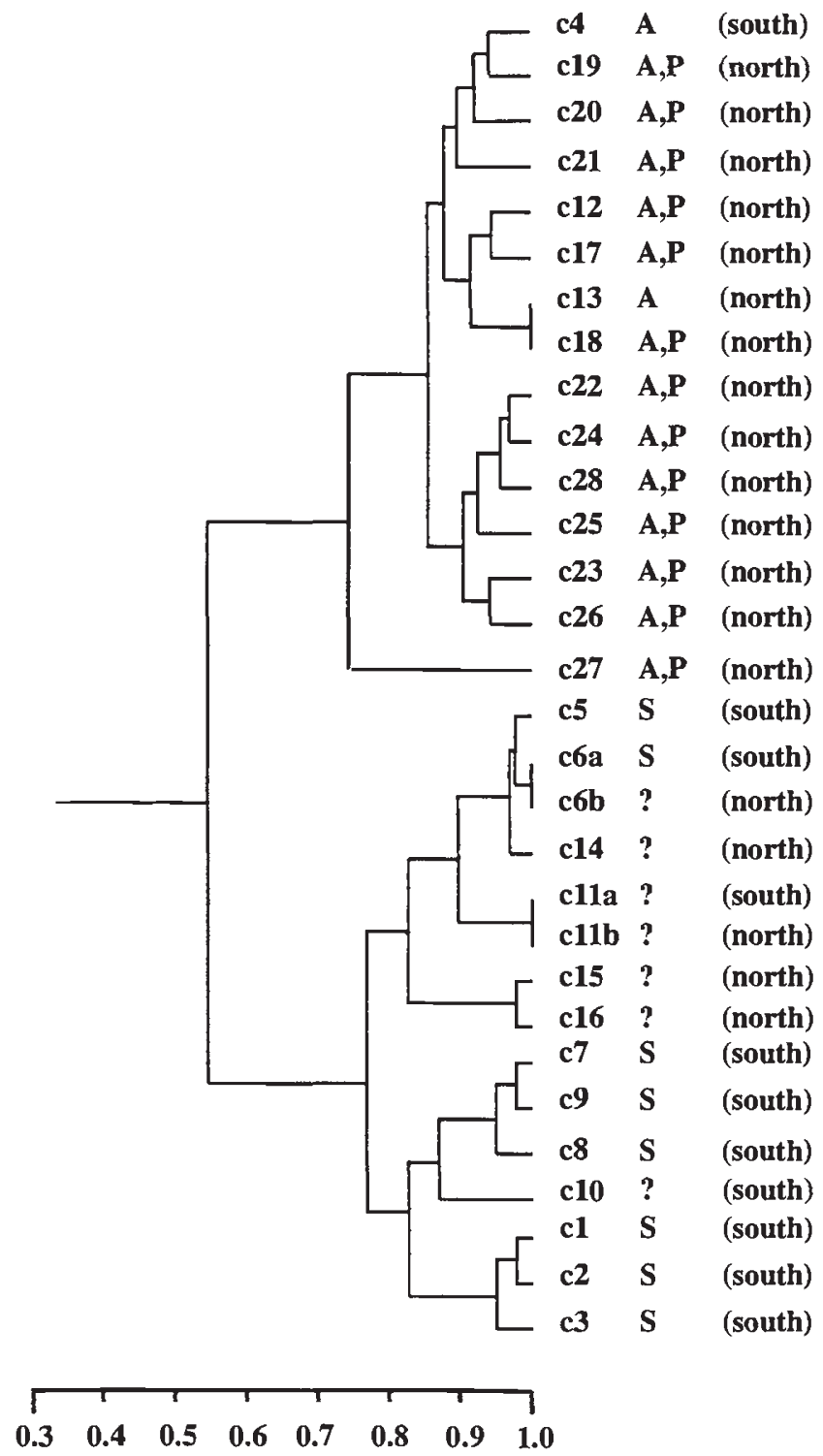

Genetic Identity

Fig. 2 UPGMA-derived dendrogram of genetic relationships among clones, using Nei's (1972) measure of genetic identity. A: asexual (obligate parthenogen); P: polyploid; S: sexual (cyclic parthenogen); ?: uncertain reproductive status. Clones are further distinguished as (south) or (north) of the Arctic circle.

found on two adjacent bluffs. Often, but not invariably, all populations on a single rock bluff were genetically identical (see Fig. 1).

The locations and assigned breeding systems for the Scandinavian samples are given in Fig. 1. There is a clear cline in breeding system, with cyclic parthenogenesis dominating in the south and obligate parthenogenesis dominating in the north. 
Table 3 Genotypes observed in Daphnia pulex populations collected from far-north Norway.

\begin{tabular}{lccccccccccc}
\hline Populations & $N$ & $A P-2$ & \multicolumn{1}{c}{ MPI } & \multicolumn{1}{c}{$P G I$} & \multicolumn{1}{c}{$P G M$} & \multicolumn{1}{c}{ LDH } & AO & AAT & $A M Y$ & GDR & Clone \\
\hline 32 & 44 & $90 / 90$ & $100 / 100$ & $90 / 100$ & $92 / \mathbf{1 0 0}$ & $\mathbf{1 0 0} / 125$ & $104 / 115$ & $\mathbf{1 0 0} / 115$ & $100 / 100$ & 0.026 & $\mathrm{c} 18$ \\
33 & 44 & $90 / 90$ & $100 / 100$ & $100 / 100$ & $100 / 100$ & $\mathbf{1 0 0} / 125$ & $96 / 115$ & $\mathbf{1 0 0} / 115$ & $100 /-10$ & 0.032 & $\mathrm{c} 19$ \\
$34-36$ & 44 & $90 / 90$ & $100 / 100$ & $100 / 100$ & $100 / 100$ & $100 / 100$ & $104 / 115$ & $\mathbf{1 0 0} / 115$ & $20 /-10$ & 0.050 & $\mathrm{c} 20$ \\
37 & 44 & $\mathbf{9 0} / 100$ & $100 / 100$ & $100 / 100$ & $92 / \mathbf{1 0 0}$ & $100 / 100$ & $96 / 115$ & $\mathbf{1 0 0} / 115$ & $100 /-10$ & 0.026 & $\mathrm{c} 21$ \\
38 & 44 & $\mathbf{9 0} / 100$ & $100 / 108$ & $100 / 100$ & $92 / \mathbf{1 0 0}$ & $100 / 100$ & $109 / 109$ & $\mathbf{1 0 0} / 115$ & $100 / 20$ & 0.032 & $\mathrm{c} 22$ \\
$39,41-43,45,46$ & 44 & $\mathbf{9 0} / 100$ & $100 / 108$ & $100 / 100$ & $92 / \mathbf{1 0 0}$ & $100 / 100$ & $115 / 115$ & $\mathbf{1 0 0} / 115$ & $100 / 20$ & 0.032 & $\mathrm{c} 23$ \\
40,44 & 44 & $\mathbf{9 0} / 100$ & $100 / 108$ & $100 / 100$ & $92 / \mathbf{1 0 0}$ & $100 / 100$ & $109 / 115$ & $\mathbf{1 0 0} / 115$ & $100 / 20$ & 0.027 & $\mathrm{c} 24$ \\
47 & 31 & $90 / 90$ & $100 / 108$ & $100 / 100$ & $100 / 100$ & $100 / 100$ & $109 / 115$ & $\mathbf{1 0 0} / 115$ & $100 / 20$ & 0.023 & $\mathrm{c} 25$ \\
& 11 & $90 / 90$ & $100 / 108$ & $100 / 100$ & $92 / 100$ & $100 / 125$ & $115 / 115$ & $\mathbf{1 0 0} / 115$ & $100 / 20$ & & $\mathrm{c} 26$ \\
& 1 & $90 / 90$ & $95 / 108$ & $90 / 100$ & $100 / 100$ & $100 / 100$ & $96 / 96$ & $100 / 100$ & $100 / 20$ & & $\mathrm{c} 27$ \\
& 1 & $90 / 100$ & $100 / 100$ & $100 / 100$ & $92 / 100$ & $100 / 100$ & $109 / 115$ & $\mathbf{1 0 0} / 115$ & $100 / 20$ & & $\mathrm{c} 28$ \\
\hline
\end{tabular}

All clones were fixed for $A P-1112, M D H 80$ and FUM 100.

The bold allele in a heterozygote indicates that that allele is probably present in more than one dose, leading to an 'unbalanced' heterozygote.

\section{Breeding system verification}

Eight UK populations (two from the East Midlands: see Ward \& Geissler, 1988; two from Scotland and four from northern England) were analysed for Mendelian segregation of hatchlings from ephippial eggs of heterozygous clones. All showed normal segregation confirming that the ephippial eggs were produced sexually.

Two Scandinavian populations, numbers 22 and 32, were analysed for ephippial segregation. These two populations are both assumed to be obligate parthenogens on the basis of fixed heterozygosity for a number of loci, one of these being PGI. PGI is a sufficiently active enzyme that individual eggs can be removed from the ephippial casing and electrophoresed directly for genotype determination. Seven mothers and eight eggs were analysed from population 22 and eight mothers and 14 eggs analysed from population 32: all mothers and all eggs were PGI 90/100 heterozygotes. This supports the supposition that these samples reproduced by obligate parthenogenesis, as similar tests on UK cyclic parthenogens clearly demonstrate $P G I$ segregation.

\section{DNA quantification}

Individuals from each of four UK populations, which were all cyclic parthenogens, had DNA levels consistent with their assumed diploid nature (Table 4). Twelve Scandinavian populations were analysed. Five of these came from Finland and three of these (populations 3, 4 and 7) had DNA levels consistent with their assumed diploid status. Population 8 was segregating for the same genotypes as population 7 , was on the same small island, yet appeared to have a higher ploidy level. It is possible that the population 8 animals were preparing to moult, which would lead to elevated DNA levels. Population 6 had a DNA level that was high for a diploid yet low for a polyploid; here the gel patterns cannot discriminate breeding system and the assumption that it is likely to be a cyclic, presumably diploid, parthenogen because it was genetically indistinguishable from a clone in the cyclic populations 7 and 8 may be unjustified. The seven Norwegian populations that were analysed all had elevated DNA levels, consistent with their presumptive polyploid status based on the presence of unbalanced heterozygotes. All seven of these populations had ploidy levels indicative of triploidy rather than tetraploidy.

\section{Comparison of genetic diversity in cyclic and obligate parthenogens}

Levels of genetic diversity within populations were quantified using Nei's (1973) $H_{\mathrm{s}}$ parameter and are given in Table 5. $H_{\mathrm{S}}$ is equivalent to expected (Hardy-Weinberg) heterozygosity: the observed heterozygosity of the obligately parthenogenetic populations would be higher than these figures as a consequence of their fixed heterozygosity for several loci. For this purpose, the polyploid populations were treated as diploids and a population with multiple doses of one allele and one dose of a second allele at a locus was treated as having two alleles with frequencies of 0.5 and 0.5 . 
Table 4 Ploidy determination of Daphnia pulex samples analysed by microdensitometry

\begin{tabular}{|c|c|c|c|c|c|}
\hline $\begin{array}{l}\text { Population } \\
\text { (clone) }\end{array}$ & $\mathrm{DNA}(\mathrm{pg})$ & $\begin{array}{l}\text { Ploidy } \\
\text { level }\end{array}$ & $\begin{array}{l}\text { Rounded } \\
\text { ploidy level }\end{array}$ & $\begin{array}{c}\text { Heterozygote } \\
\text { patterns } \dagger\end{array}$ & $\begin{array}{l}\text { Reproductive } \\
\text { mode } \neq\end{array}$ \\
\hline \multicolumn{6}{|l|}{ UK populations } \\
\hline Yorkshire 1 & 0.66 & 1.78 & 2 & B & Cyclic, diploid \\
\hline Cumbria 1 & 0.88 & 2.38 & 2 & B & Cyclic, diploid \\
\hline E. Midlands 1 & 0.82 & 2.22 & 2 & B & Cyclic, diploid \\
\hline E. Midlands 2 & 0.75 & 2.04 & 2 & B & Cyclic, diploid \\
\hline \multicolumn{6}{|c|}{ Scandinavian populations } \\
\hline $3(\mathrm{c} 4)$ & 0.72 & 1.93 & 2 & B & Obligate, diploid \\
\hline (c4) & 0.72 & 1.96 & 2 & B & Obligate, diploid \\
\hline (c7) & 0.99 & 2.68 & 3 & - & Probable cyclic, probable diploid \\
\hline $7 \quad(c 7-9)$ & 0.84 & 2.28 & 2 & B & Cyclic, diploid \\
\hline $8 \quad(c 7-9)$ & 1.12 & 3.03 & 3 & B & Cyclic, probable diploid \\
\hline 13 (c6b) & 1.03 & 2.78 & 3 & - & Uncertain \\
\hline (c12) & 1.10 & 2.98 & 3 & $\mathrm{U}$ & Obligate, polyploid \\
\hline$(\mathrm{c} 17)$ & 1.12 & 3.04 & 3 & $\mathrm{U}$ & Obiigate, polyploid \\
\hline $32(\mathrm{c} 18)$ & 1.10 & 2.98 & 3 & $\mathrm{~B}, \mathrm{U}$ & Obligate, polyploid \\
\hline 33 (c19) & 1.09 & 2.96 & 3 & $\mathrm{U}$ & Obligate, polyploid \\
\hline (c21) & 1.13 & 3.06 & 3 & $\mathrm{U}$ & Obligate, polyploid \\
\hline (c23) & 1.06 & 2.87 & 3 & $\mathrm{~B}, \mathrm{U}$ & Obligate, polyploid \\
\hline
\end{tabular}

$\nmid B$ : balanced heterozygote(s); U: unbalanced heterozygote(s).

$\ddagger$ As determined from genetic population structure and heterozygote band intensities. See text.

The heightened genetic diversity of the obligately parthenogenetic populations is readily apparent. Over all 11 loci, mean $H_{\mathrm{S}}$ for the obligates is about five times that of the cyclics. Particularly striking differences are seen at $P G M, L D H, A A T, A M Y$ and $A O$. At the first four of these loci, the 100 allele is by far the most frequent in cyclic populations in Scandinavia and the UK. With respect to $A O$, most UK populations are fixed for $A O 100$ although those in Cumbria were fixed for $A O 104$ and a few populations contained $A O 96$ or AO 90.

At $P G M$, allele 92 is present in 18 of 28 asexual populations, always in a heterozygous condition with PGM 100, but is absent from all cyclic populations in Scandinavia or the UK. Similarly, $L D H 125$ is present in 15 asexual populations, always heterozygously with $L D H 100$, while being absent from cyclic populations. $A A T 115$ is present in all 28 asexual populations, almost always in a fixed heterozygous state with $A A T$ 100 , but is absent from all cyclic populations. $A M Y 10$ and $A M Y 20$ also characterize asexual populations, again usually in heterozygous condition with $A M Y 100$, although $A M Y 20$ has been observed in six of the UK cyclic populations (M. A. Bickerton, unpublished data). $A O 115$ is absent from cyclic populations but is found in all Scandinavian obligate populations, sometimes homozygously and sometimes heterozygously with $A O$ 104 or $A O 109$.
Table 5 Comparison of mean genetic diversity per population $\left(H_{\mathrm{S}}\right)$ in cyclic and obligate parthenogenetic populations

\begin{tabular}{lccc}
\hline & & \multicolumn{2}{c}{ Scandinavian } \\
\cline { 3 - 4 } & Cyclic & Cyclic & Obligate \\
\hline$n$ & 43 & \multicolumn{1}{c}{7} & 28 \\
$A P-1$ & 0.020 & 0 & 0.014 \\
$A P-2$ & 0.265 & 0.063 & 0.301 \\
$M P I$ & 0.070 & 0.068 & 0.180 \\
$P G I$ & 0.082 & 0 & 0.062 \\
$P G M$ & 0.006 & 0 & 0.311 \\
$L D H$ & 0 & 0 & 0.258 \\
$M D H$ & 0.009 & 0.104 & 0 \\
$F U M$ & 0 & 0.034 & 0 \\
$A O$ & 0.039 & 0.122 & 0.309 \\
$A A T$ & 0 & 0 & 0.499 \\
$A M Y$ & 0.038 & 0.047 & 0.304 \\
Mean & 0.048 & 0.040 & 0.203 \\
\hline
\end{tabular}

$n$ : number of populations.

These genetic differences among populations are reflected in the substantial genetic differences among the clones that comprise these populations. The 27 Norwegian and Finnish clones fall into two very 
distinct groups (Fig. 2), separating at a genetic identity (Nei, 1972) of 0.56 . One of these groups (group A) comprised all those clones designated as obligate parthenogens and the other group (group B) those designated as cyclic parthenogens together with those that could not be classified.

The clear separation of the clones into two groups suggests that the clones of uncertain reproductive mode group might well be cyclic parthenogens, as they group so closely with those so identified. However, such a conclusion may well be premature. The group B clones form two subgroups. In one of these subgroups, six of the seven member clones clearly reproduce cyclically and it seems very reasonable to conclude that all seven clones here represent cyclic parthenogens. In the other subgroup, only two of eight member clones have been designated as cyclic and in fact these two clones showed significant Hardy-Weinberg deviations in the population where they co-occurred. Five of the eight clones come from a northern area where no cyclic parthenogens have been clearly identified and two of the clones are LDH 100/125 heterozygotes (c14, c15), a genotype otherwise associated with obligate parthenogenesis in Scandinavia. It may well be that some clones in this subgroup do reproduce by obligate parthenogenesis.

Fifteen obligate parthenogenetic clones make up group A. Two of these (c13 and c18) had the same genotype but one showed balanced heterozygotes (c13) and the other unbalanced heterozygotes (c18). Fourteen of the 15 clones were $A A T$ 100/115 heterozygotes. The exception was $\mathrm{c} 27$, a clone heterozygous for three other loci (MPI, PGI, AMY) but represented by only a single individual. This clone groups comparatively loosely (genetic identity of around 0.74 ) with the other obligate parthenogens (Fig. 2). Six of the 11 far-north Norwegian clones (c22-26, c28) formed a monophyletic subgroup with group $\mathrm{A}$ and are characterized by $A M Y 100 / 20$ heterozygosity. Twelve of the 15 asexual clones were designated as polyploids on the basis of their allozyme patterns, one (c4) was designated as a diploid on the the basis of both allozyme patterns and ploidy determinations and two (c13, c27) were of uncertain ploidy status.

\section{Discussion}

There is a clear south-north cline in breeding system in European $D$. pulex. The most southerly populations (those from the UK plus limited sampling from Denmark and south Sweden) are cyclic parthenogens whereas the more northerly populations all reproduce by obligate parthenogenesis. Mid-Scandinavia appears to be a zone of transition, with both systems present.
This shift in breeding system is accompanied by a shift in ploidy levels, from diploidy in the south to polyploidy in the north. Most of the obligate parthenogens are polyploid, although at least one diploid obligate parthenogen was identified in mid-Scandinavia. Populations from the arctic islands of Svalbard (Spitzbergen), about $1000 \mathrm{~km}$ north of north Norway, are also obligate parthenogens (Olofsson, 1918; Hobaek et al., 1993), with most if not all clones being polyploid (Hobaek et al., 1993; Weider \& Hobaek, 1994).

Asexual populations belonging to the $D$, pulex group in temperate North America fall into two genetically distinguishable groups (Hebert et al., 1989a, 1993). One of these groups consists of clones assigned to $D$. pulex s.s., while the other group represents $F_{1}$ hybrids between this species and $D$. pulicaria. Both groups appear to have arisen polyphyletically, apparently as a result of the transmission of a gene producing sex-limited meiosis suppression (Innes \& Hebert, 1988). There is a complex geographical pattern of breeding system variation in temperate North American populations, with asexual populations of $D$. pulex dominating in the east and sexual populations dominating the west. There is, however, a clear dominance of asexual populations in the Canadian Arctic, producing a pattern in the eastern half of the continent which resembles that noted in this study, with cyclic parthenogens dominant in the south and obligates in the north.

The clonal richness of the asexual populations of Scandinavian D. pulex (mean 1.2 clones/pond, $N=28$ ponds, 15 clones) is the lowest yet recorded, lower than Svalbard (mean 1.8 clones/pond, $N=18$ ponds, 49 clones, Weider \& Hobaek, 1994) and Churchill, in the low Arctic region of Canada (mean 1.5 clones/pond, $N=147$ ponds, 16 clones, Weider \& Hebert, 1987) and much lower than Igloolik, in the Canadian high Arctic (mean 4.5 clones/pond, $N=179$ ponds, 75 clones, Weider et al., 1987). Asexually reproducing populations in the Great Lakes region of Canada average 2.8 clones/pond (156 ponds, Hebert et al., 1988).

These differences in clonal diversity are likely to be related to a multitude of factors. The above average richness of the asexual populations in the temperate Great Lakes region may reflect their longer seasonality and enhanced biotic complexity. The ponds comprising the asexual populations from Svalbard and Igloolik are tundra ponds, some of which are several hundred square metres in area and are therefore not directly comparable to the rock bluff populations of Scandinavia. The Churchill populations are physically the most similar to those we sampled in Scandinavia as they too mostly occupied small rock bluff habitats. The 
Churchill ponds on average held 1.5 clones per pond compared with 1.2 clones from Scandinavia and are likely to be somewhat younger at no more than 3000-4000 years (L. J. Weider, personal communication) compared with around 10000 years for the latter (R. Vainola, personal communication). The greater diversity of the Churchill ponds could be related to their relative youth: it is possible that when ponds are first formed they become colonized by Daphnia of diverse genotypes and that as populations age particular clones dominate either through selection or genetic drift. Interestingly, the one man-made pond from far-north Norway (population 47) was the only one from that region that was multiclonal and it contained (at least) four clones. A previous study found no significant relationship between pond age and clonal diversity of Igloolik island (Weider et al., 1987) but this topic deserves further attention.

While recombination is absent from these asexual or obligately parthenogenetic clones, there is clearly substantial genetic variation between clones. In this relatively limited sampling of Scandinavian populations, 15 different asexual clones were identified. Clearly this is a severe underestimate of the actual number, which can only be more accurately gauged by sampling further populations and further loci. Interestingly, these asexual clones have a number of features in common. Perhaps most striking is the fact that 14 of them were $A A T$ 100/115 heterozygotes, while all the cyclic populations sampled in Scandinavia and the UK were homozygous for $A A T 100$. Seven asexual clones were $L D H$ 100/125 heterozygotes and nine were PGM 92/ 100 heterozygotes, with alleles $L D H 125$ and PGM 92 being absent from all positively identified cyclic populations. This heterozygosity for common pulex alleles together with alleles not found in sexually reproducing pulex populations suggests that these obligate parthenogens arose following one or more hybridization events with a genetically divergent taxon. This as yet unidentified taxon could well be homozygous (or nearly so) for the $A A T 115$ allele and polymorphic for $L D H 100$ and 125 . It could also be polymorphic for $A M Y 100$ and 20, since $A M Y 20$ is present in six asexual clones from north Norway but is absent in all other Scandinavian asexual and sexual clones (although it has been seen in some UK populations of $D$. pulex from Yorkshire (M. A. Bickerton, unpublished data). While it would be rash to suppose that the 15 different asexual clones arose from 15 different hybridization events as some may be mutational derivatives, the fact that many clones differ by several loci does suggest polyphyletic origins of asexuality. When clones are clustered according to their genetic similarities (Fig. 2), eight asexual clones fall into one subcluster, six into another and one by itself. This suggests that at least three hybridization events occurred. Asexuality in temperate North American populations of $D$. pulex has also arisen polyphyletically from crosses between $D$. pulex and the closely related species $D$. pulicaria: in this case supporting evidence comes from both nuclear and mitochondrial DNA analysis (Hebert et al., 1989, 1993; Crease et al., 1989).

Twelve of the 15 asexual clones (including ten of the 11 clones from the far north) showed unbalanced heterozygotes at one or more loci, implying polyploidy. Direct DNA quantification studies on six of these clones indicated that they are triploids, although polyploid clones with similar DNA quantities from some other arctic regions have been assigned tetraploid status (Beaton \& Hebert, 1988). Chromosome counts would be needed to confirm that the Scandinavian polyploid clones are indeed triploids and not tetraploids.

There are many other examples of geographical variation in reproductive mode in European invertebrates (Vandel, 1928; Hughes, 1989). In most cases, obligately parthenogenetic animals occupy, more northerly latitudes, higher altitudes or otherwise less hospitable areas than their sexual ancestors. The selective forces responsible for establishing and maintaining such clines remain uncertain, although the twofold increase in reproductive rate of asexuals in comparison with sexuals may be especially advantageous under arctic conditions where the time available for reproduction and population growth will be very limited and may compensate for the lack of recombinant genotypes in these populations.

The significance of the change in ploidy levels is also unclear. In $D$. pulex, obligate parthenogens can be either diploids or polyploids, with polyploidy increasing in prevalence with increasing latitude (present paper; Weider, 1987; Weider et al., 1987; Hebert et al., 1988; Hobaek et al., 1993). Theoretical studies indicate that polyploid organisms are expected to mature more slowly and at larger sizes than closely related diploids (Cavalier-Smith, 1978), and empirical studies, including one on D. pulex, confirm this expectation (Beatty, 1957; Lewis, 1980; Weider, 1987). An increased generation time is presumably a marked disadvantage in a short-lived arctic habitat, so why do polyploid clones dominate at high latitudes? Polyploid asexual populations on average have higher heterozygosity than diploid asexuals (Suomalainen et al., 1987) and it has been suggested that this may, in some undefined way, increase fitness in extreme environments. But it may also be that polyploid clones are more resistant to the deleterious effects of mutations than diploid clones. All asexual clones, irrespective of 
ploidy level, remorselessly accumulate deleterious mutations and irreversibly decline in fitness, in a process known as Muller's ratchet (Maynard Smith, 1978). Polyploid asexuals will accumulate more mutations than diploid lineages but if these mutations are recessive, polyploid lineages would be more resistant to their effects and would have longer clonal life-spans than diploids (Lokki, 1976). If obligate parthenogenesis arises initially through hybridization, as seems likely, then diploid parthenogens might be expected to be continuously generated in zones of overlap between the sexual or cyclically parthenogenetic species and these short-lived but continuously regenerated diploid sexual clones would outcompete any polyploids that might arise. However, with increasing distance from the hybridization zone, in short-lived extreme habitats favouring asexuality, polyploid clones would persist longer than diploid clones and would therefore displace them. Such a model, or a variant thereof, might explain why both asexuality and polyploidy are favoured in extreme conditions.

\section{Acknowledgements}

R.D.W. and M.A.B. thank the Natural Environment Research Council for their support of this work, the Royal Society for supplying a Travel Grant and are very grateful for the hospitality shown by various field stations in Scandinavia. These include the Tjarno Marine Biological Laboratory, the Songli station of the Norwegian Institute for Nature Research, the Abisko Scientific Research Station of the Royal Swedish Academy of Sciences, the Kevo Subarctic Research Institute of the University of Turku, the Archipelago Research Institute of the University of Turku and the Einar Naumann Limnological Laboratory of the University of Lund. The Natural Sciences and Engineering Research Council of Canada provided funding to P.D.N.H. which made possible the genome size studies. We thank Peter Grewe for assistance with the figures.

\section{References}

BEATON, M. J. AND HEBERT, P. D. N. 1988. Geographical parthenogenesis and polyploidy in Daphnia pulex Leydig. Am. Nat., 132, 837-845.

BEATON, M. J. AND HEBERT, P. D. N. 1990. Miniature genomes and endopolyploidy in cladoceran crustaceans. Genome, 32, 1048-1053.

BeATTy, R. A. 1957. Parthenogenesis and Polyploidy in Mammalian Development. Cambridge Monographs in Experimental Biology, no. 7. Cambridge University Press, Cambridge.

BELL, G. 1982. The Masterpiece of Nature: the Evolution and Genetics of Sexuality. Croom Helm, London.
CAVALIER-SMITH, T. 1978. Nuclear volume control by nucleoskeletal DNA, selection for cell volume and cell growth rate, and the solution of the DNA c-value paradox. J. Cell. Sci., 34, 247-278.

Crease, T. J., Stanton, D. J. AND hebert, P. D. N. 1989. Polyphyletic origins of asexuality in Daphnia pulex. II. Mitochondrial DNA variation. Evolution, 43, 1016-1026.

GLESENER, R. R. AND TILMAN, D. 1978. Sexuality and the components of environmental uncertainty: clues from geographic parthenogenesis in terrestrial animals. Am. Nat., 112, 659-673.

HEBERT, P. D. N. AND BEATON, M. J. 1989. Methodologies for Allozyme Analysis using Cellulose Acetate Electrophoresis. Helena Labs, Beaumont, Texas.

HEBERT, P. D. N., BEATON, M. J., SCHWARTZ, S. S. AND STANTON, D. J. 1989a. Polyphyletic origins of asexuality in Daphnia pulex. I. Breeding system variation and levels of clonal diversity. Evolution, 43, 1004-1015.

HEBERT, P. D. N., SCHWARTZ, S. S. AND HRBACEK, J. 1989 b. Patterns of genotypic diversity in Czechoslovakian Daphnia. Heredity, 62, 207-216.

HEBERT, P. D. N., SCHWARTZ, S. S. WARD, R. D. AND FINSTON, T. L. 1993. Macrogeographic patterns of breeding system diversity in the Daphnia pulex group. 1. Breeding systems of Canadian populations. Heredity, 70, 148-161.

HEBERT, P. D. N., WARD, R. D. AND WEIDER, L. J. 1988. Clonal diversity patterns and breeding system variation in Daphnia pulex, an asexual-sexual complex. Evolution, 42, 1024-1035.

HOBAEK, A., WEIDER, L. J. AND WOLF, H. G. 1993. Ecological genetics of Norwegian Daphnia. III. Clonal richness in an arctic apomictic complex. Heredity, 71, 323-330.

Hughes, R. N. 1989. A Functional Biology of Clonal Animals. Chapman and Hall, London.

INNES, D. J. AND HEBERT, P. D. N. 1988. The origin and genetic basis of obligate parthenogenesis in Daphnia pulex. Evolution, 42, 1024-1035.

LEWIS, W. H. (ED.) 1980. Polyploidy: Biological Relevance, vol. 13. Basic Life Sciences, Plenum Press, New York.

LOKKI, J. 1976. Genetic polymorphism and evolution in parthenogenetic animals. VIII. Heterozygosity in relation to polyploidy, Hereditas, 83, 65-72.

LYNCH, M. 1983. Ecological genetics of Daphnia pulex. Evolution, 37, 358-374.

maynard SMith, J. 1978. The Evolution of Sex. Cambridge University Press, Cambridge.

NEI, M. 1972. Genetic distance between populations. Am. Nat., 106, 283-292.

NE1, M. 1973. Analysis of gene diversity in subdivided populations. Proc. Natl. Acad. Sci. U.S.A., 70, 3321 3323.

olofsson, o. 1918. Studien uber die Susswasserfauna Spitzbergens. Zool. Bidr. Uppsala, 6, 183-646.

RUVINSKY, A. O., PERELYGIN, A. A., LOBKOV, YU.I. AND BELYAEV, D. K. 1986. Factors organising and maintaining polymorphism in a cyclic parthenogenetic species: Daphnia pulex. Heredity, 57, 15-22.

SUOMALAINEN, E. 1962. Significance of parthenogenesis in the evolution of insects. Ann. Rev. Entomol., 7, 349-366.

SUOMALAINEN, E. 1969. Evolution in parthenogenetic Curculionidae. Evol. Biol., 3, 261-296. 
SUOMAlainen, E., SAURA, A. AND LOKKI, J. 1987. Polyploidy in association with parthenogenesis. In: Suomalainen, E., Saura, A. and Lokki, J. (eds) Cytology and Evolution in Parthenogenesis, pp. 71-112. CRC Press, Boca Raton, Florida.

VANDEL, A. 1928. La parthénogénèse géographique: contribution a l'étude biologique et cytologique de la parthénogénèse naturelle. Bull. Biol. France et de la Belgique, 62, 164-281.

WARD, R. D. AND GEISSLER, P. A. 1988. Reproductive mode in populations of Daphnia pulex and Daphnia obtusa from the East Midlands of Britain. Freshw. Biol., 20, 69-73.

WEIDER, L. J. 1987. Life history variation among low-arctic clones of obligately parthenogenetic Daphnia pulex: a diploid-polyploid complex. Oecologia, 73, 251-256.

WEIDER, L. J., BEATON, M. J. AND HEBERT, P. D. N. 1987. Clonal diversity in high-Arctic populations of Daphnia pulex, a polyploid apomictic complex. Evolution, 41, 1335-1346.

WEIDER, L. J. AND HEBERT, P. D. N. 1987. Microgeographic genetic heterogeneity of melanic Daphnia pulex at a low Arctic site. Heredity, 58, 391-399.

WEIDER, L. J. AND HOBAEK, A. 1994. Molecular biogeography of clonal lineages in a high-arctic apomictic Daphnia complex. Mol. Ecol. (in press).

willams, G. C. 1975. Sex and Evolution, Princeton University Press, Princeton. 